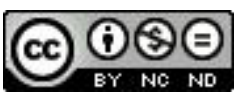

\title{
Saberes Quilombolas: um estudo no processo de produção da farinha de mandioca
}

\section{Quilombola Ways of Knowing: a study about the production process of the cassava flour}

\author{
Idemar Vizolli* \\ Rosa Maria Gonçalves Santos** \\ Renato Francisco Machado ${ }^{* * *}$
}

\begin{abstract}
Resumo
Esse estudo tem como objetivo identificar ideias matemáticas presentes no processo de produção da farinha de mandioca na Comunidade Quilombola Lagoa da Pedra, Arraias, TO. Autores como D'Ambrosio, Knijnik, entre outros, indicam que as pessoas, em suas práticas cotidianas, encontram modos próprios para solucionar problemas que envolvem conceitos matemáticos e que esses modos apresentam traços típicos de sua cultura. Inspirados na metodologia da pesquisa etnográfica, os dados e informações foram coletados por meio de filmagens, fotos, anotações, observações, entrevistas e na participação no processo de fabricação da farinha de mandioca. Os resultados indicam que os Quilombolas da Lagoa da Pedra desenvolveram uma série de conhecimentos matemáticos que se manifestam no processo da produção de farinha de mandioca, entre os quais se destaca a utilização de sistema de medidas convencionais como, por exemplo, metro, tonelada, quilograma e medidas de tempo, entre outras; e não convencionais como, por exemplo, vara, braça, quadro, tarefa, entre outras.
\end{abstract}

Palavras-chave: Quilombolas. Farinha de Mandioca. Ideias Matemáticas.

\footnotetext{
* Doutor pela Universidade Federal do Paraná (UFPR). Professor na Universidade Federal do Tocantins (UFT), campus de Arraias, Arraias, TO, Brasil. Endereço para correspondência: Avenida Universitária, s/n, Universidade Federal do Paraná (UFT), Centro, CEP: 77330-000. Arraias, TO, Brasil. E-mail: idemar@uft.edu.br.

** Acadêmica do Curso de Matemática na Universidade Federal do Tocantins (UFT), campus de Arraias e bolsista do CNPq. Arraias, TO, Brasil. Endereço para correspondência: Avenida Universitária, s/n, Universidade Federal do Paraná (UFT), Centro, CEP: 77330-000. Arraias, TO, Brasil. E-mail: rosamuft@uft.edu.br

${ }^{* * * *}$ Professor na Rede Pública do Estado do Tocantins. Endereço para correspondência: Rua Geral, Lagoa da Pedra, CEP: 77330-000. Arraias, TO, Brasil. E-mail: rfmachado2@hotmail.com.
} 


\begin{abstract}
This study aimed to recognize mathematical ideas in the process of producing cassava flour in the Lagoa da Pedra Quilombola Community, in Arraias, TO. Authors such as D'Ambrosio, Knijnik, among others, have described how people, in their day-today practices, find their own ways of solving problems that involve mathematical conceptions, and that these ways are peculiar to their culture. Using an ethnographic research approach, the data and the information collected included video recordings, photos, notations, observations, interviews, and participation in the fabrication process of the cassava flour. The results show that the Lagoa da Pedra Quilombolas developed a series of mathematical conceptions that are manifested in the cassava flour production process, such as: the use of a conventional measurement system, for example, meter, ton, kilogram and time measures, among others; and non-conventional measures such as, vara, braça, quadro, tarefa.
\end{abstract}

Keywords: Quilombolas. Cassava Flour. Mathematic Ideas.

\title{
1 A escolha do terreno
}

A literatura indica que a matemática presente em contextos socioculturais tem sido tema de pesquisas no campo da Educação Matemática. Na tentativa de compreender as práticas sociais de grupos culturais não hegemônicos, e os saberes matemáticos nelas envolvidos, muitos estudiosos tem se inspirado no Programa da Etnomatemática para desenvolver seus estudos. De acordo com D’Ambrosio (2002, p. 22), "o cotidiano está impregnado dos saberes e fazeres próprios da cultura. A todo instante, os indivíduos estão comprando, classificando, quantificando, medindo, (...) e, de algum modo, avaliando, usando os instrumentos materiais e intelectuais que são próprios à sua cultura." Nesse sentido, os fazeres do cotidiano, presentes numa dada cultura, envolvem ideias matemáticas próprias, as quais se manifestam nos fazeres das pessoas. De acordo com Vilela (2007), podemos falar em conhecimentos com características próprias, entendendo a matemática como prática social.

O Programa Etnomatemática volta seu olhar à dicotomia que, muitas vezes, se estabelece entre cultura erudita e cultura popular. Sob o entendimento de que a cultura é um bem imaterial e se constitui como parte integrante das populações, rejeita toda a espécie de dicotomia entre tais categorias (SILVA, 2002).

Tanto a matemática produzida na academia como aquela que se manifesta nos saberes populares se caracterizam como Etnomatemática, embora a segunda 
não faça parte da academia, ambas são produções de grupos específicos. Ao analisar textos-documentos que tratam matemáticas praticadas por diferentes grupos culturais ou de profissionais, coloca-se que "[...] estão sempre em diálogo conflitivo e/ou conciliatório com a matemática escolar ou acadêmica, ou ainda, com a matemática entendida como produto ou domínio de conhecimentos." (VILELA, 2007, p. 218). De todo modo, são conhecimentos diferentes em que se faz uso de lógicas e processos, muitas vezes diferentes da matemática acadêmica, o que não significa que não sejam conhecimentos matemáticos. A Etnomatemática tem interesse em compreender as práticas como processo dinâmico, nos quais as ambiguidades, as diferenças e as divergências dão o tônus às discussões e reflexões sobre as problemáticas (D’AMBROSIO, 2002).

O desenrolar do cotidiano na Comunidade Quilombola Lagoa da Pedra é repleto de saberes culturais, determinado pelo modo de ser e viver das pessoas, assim como das relações que estabelecem entre si e com o meio ambiente. Por meio das atividades com o ambiente e atendendo às necessidades de sobrevivência, emergem saberes e fazeres matemáticos. Trata-se de um cotidiano impregnado de saberes e fazeres próprios da cultura da Comunidade. De acordo com Jesus (2007), as necessidades que uma comunidade tem para se estabelecer e se organizar de modo independente geram uma série de conhecimentos, inclusive de matemática, que se manifestam na difusão da cultura, nos hábitos alimentares, na dança, na pintura, no artesanato, nos rituais religiosos, na produção de alimentos, no cultivo da lavoura, entre outros.

As formas de envolvimento com as atividades do ambiente estão presentes na maioria das atividades diárias das pessoas e possibilitam o desenvolvimento de conhecimentos matemáticos, muitos deles repassados pelos antepassados por meio da oralidade: Não tinha estudo não, contar todo mundo sabia um, dois, treis, quatru, cincu, seis, (...). O dinheiro tinha a menus duzentus réis, quinhentu réis. A gente sabia contá moçu.(Liocadio F. Machado $^{1}$ )

Mesmo que na escola sejam ensinadas as unidades de medidas oficiais, em seu dia-a-dia as pessoas continuam fazendo uso de unidades não convencionais; por exemplo, $\mathrm{x}$ minutos a pé, referindo-se à distância e um quadro de 15 ou uma tarefa, para tratar de medidas agrárias. Assim, a matemática acadêmica é utilizada nas situações comerciais e nas transações bancárias, o que é imprescindível para todas as pessoas. Exemplificando: Medir farinha era tudo no prato, um prato era dois litros, prato de pau, num tinha otra

\footnotetext{
${ }^{1}$ Um dos patriarcas da Comunidade Quilombola Lagoa da Pedra.
} 
medida (...). Na roça era a braça, a tarefa era lá, 15, 15 braça, 15 assim, 15 assim, 15 assim, 15 assim (Liocadio F. Machado).

A Comunidade Quilombola Lagoa da Pedra localiza-se na zona rural, há 35 quilômetros da sede do município de Arraias, TO, onde são cultivados uma série de produtos agrícolas (arroz, mandioca, feijão, milho, cana de açúcar, batata doce, melancia, abóbora e árvores frutíferas) e criam-se animais (equinos, suínos bovinos e aves). Assim, grande parte da alimentação das pessoas é produzida pelas próprias famílias.

A mandioca é uma das principais fontes de alimento. Dela se produz a farinha, que é bastante utilizada na culinária. O processo de produção da farinha de mandioca é essencialmente artesanal e, mesmo nos dias atuais, são utilizados objetos (artefatos) como quibano, peneira, balaio, cocho, prensa, gamela, entre outros. Ainda que não conheçam a matemática oficial, as pessoas fazem uso de ideias/conceitos matemáticos que podem ser modelados.

Esse panorama nos impeliu a empreender uma investigação para identificar ideias matemáticas que se manifestam no processo de produção da farinha de mandioca na Comunidade Quilombola Lagoa da Pedra.

\section{Preparando o solo}

Ao atuar na formação de professores que ensinam matemática, percebemos que estes dificilmente conseguem auscultar a forma como os alunos organizam seu pensamento para solucionar um dado problema e que, por vezes, não conseguem perceber as relações que os alunos estabelecem entre a matemática da vida prática e a matemática ensinada na escola. Tais constatações encontram eco nos Parâmetros Curriculares Nacionais, quando assinalam que, muitas vezes, "as necessidades cotidianas fazem com que os alunos desenvolvam uma inteligência essencialmente prática, que permite reconhecer problemas, buscar e selecionar informações, tomar decisões e, portanto, desenvolver uma ampla capacidade para lidar com a atividade matemática." (BRASIL, 1997, p. 37)

"A forma matemática de raciocinar desenvolvida pelos negros no Brasil pode em muito contribuir para a construção de identidades matemáticas próprias." (COSTA; SILVA, 200[5], p. 98). Nesse contexto, a matemática deve ser vista como uma forma de preparação dos cidadãos para inclusão na sociedade em que vivemos. 
O ensino da matemática pode ter uma importante contribuição na reafirmação e, em numerosos casos, na restauração da dignidade cultural das crianças. O essencial do conteúdo dos programas atuais repousa sobre uma tradição estrangeira aos alunos. De outro lado, eles vivem em uma civilização dominada pela matemática e por meios de comunicação sem precedentes, mas as escolas lhes apresentam uma visão de mundo baseada em dados. (D’AMBROSIO, 200[5], p. 7).

Constatamos também que, muitas vezes, a matemática é vista como uma disciplina abstrata e separada das situações cotidianas e seu ensino ancorase na verbalização e memorização de regras, macetes e fórmulas. Em outros termos, na prática pedagógica das escolas ainda predominam os métodos tradicionais (memorização), onde o professor acredita que a aprendizagem ocorre apenas pela prática e repetição de exercícios ou no momento da prova. $\mathrm{O}$ resultado desta prática faz com que os alunos não trabalhem conceitos matemáticos de modo significativo, gerando medo ou mesmo aversão à matemática (BRITO 2001).

Contrastando com a precisão e o rigor da matemática acadêmica ou científica, fala-se em matemática popular. Esta se preocupa em analisar os procedimentos utilizados na solução de questões práticas e aplicadas, denotando pouca preocupação com a demonstração formal.

Ao ministrar aulas de matemática na Educação Básica, em escolas públicas, percebemos que alguns alunos utilizam modos diferentes para organizar dados e informações presentes em determinados problemas propostos em sala de aula. Muitas vezes, na organização dos dados e informações, assim como nos procedimentos adotados no processo de solução de determinados problemas, os alunos utilizam modos diferentes daqueles que os professores conhecem ou que são apresentados nos livros didáticos.

Nossas vivências e experiências Quilombolas permitem dizer que a população da Lagoa da Pedra desenvolveu modos próprios para solucionar uma série de problemas de seu contexto social. O modo de saber do povo negro brasileiro constitui um saber (re)elaborado pelas pessoas a partir da diversidade cultural africana e da convivência com as novas realidades políticas e sociais (COSTA; SILVA, 2005). 


\section{A oficina de farinha de mandioca: caracterização da pesquisa}

Como se trata de uma pesquisa que apresenta características de trabalhos com enfoque antropológico, há que se tomar cuidados com relação às narrações de fatos, dos nomes, dos lugares, das datas e dos acontecimentos relevantes, mantendo, sempre, a preocupação de preservar essas memórias arranjadas, sem perder de vista as posturas ideológicas presentes. (LÉVI-STRAUSS, 1975; DAMASCENO, 2005).

Esta pesquisa consistiu de um estudo em que os pesquisadores procuraram compreender as circunstâncias e o contexto da pesquisa, levando em consideração os sentidos, os sentimentos e as emoções dos atores envolvidos no processo. Considera-se, portanto, os sujeitos da pesquisa como seres produtores de conhecimentos e práticas (CHIZOTTI, 1991). Estamos falando de uma pesquisa qualitativa, em que se estuda o fenômeno em seu estado natural, levando-se em conta todos os componentes de uma dada situação em suas interações (ANDRÉ, 2005). Trata-se, mais precisamente, de uma pesquisa etnográfica localizada no ramo da antropologia. Ramo esse "que acumula conhecimentos sobre realidades sociais e culturais peculiares, delimitadas no tempo e no espaço" (EZPELETA; ROCKWELL, 1989, p. 32).

De acordo com Malinowski (1976), a pesquisa etnográfica perpassa por três momentos não desconexos: o primeiro consiste na delimitação do esquema da vida do grupo cultural em estudo; no segundo observam-se os fenômenos da vida cotidiana do grupo; e o terceiro, em que se coletam dados e informações relativos aos saberes e fazeres do grupo. Diante do exposto, procuramos estabelecer um conjunto de procedimentos metodológicos que pudessem reunir o máximo de informações fundamentais ao desenvolvimento do estudo em epígrafe.

Destarte, os contatos iniciais ocorreram por intermédio de vínculos de amizades com colegas de trabalho, ao participarem de atividades festivas na Comunidade Quilombola Lagoa da Pedra. Assim, passamos a nos inteirar de fazeres e saberes, dentre eles a produção da farinha de mandioca. Ao nos interessar pelo assunto, fomos convidados a conhecer mais de perto a vida na comunidade, o que nos possibilitou, dentre outras coisas, participar ativamente no processo de produção da farinha de mandioca.

Ao participar desse processo, coletamos os dados utilizando recursos como filmagens, gravações, anotações de observações, participação em eventos realizados pela comunidade e entrevistas. Procedimentos esses, característicos de pesquisas de cunho etnográficos. 


\subsection{A pesquisa de campo}

O fato de desenvolvermos outras pesquisas na comunidade facilitou, sobremaneira, o processo de coleta de dados. Ficou combinado com pessoas da Comunidade que, quando alguém fosse produzir farinha, os pesquisadores seriam informados e estariam autorizados a participar do processo de produção da mesma. O contato direto dos pesquisadores com as pessoas da comunidade gerou laços de amizades e confiança, o que tem sido fundamental no processo de desenvolvimento das pesquisas.

A interação entre as partes permitiu que acurássemos nosso olhar diante da complexidade de saberes e fazeres que, muitas vezes, se traduzem em peculiaridades subjetivas dos moradores da lagoa da Pedra diante do seu envolvimento na produção da farinha de mandioca.

Para obter mais dados e informações foram efetuadas perguntas, cujas respostas remetem: à época de plantio e colheita da mandioca; ao tempo necessário para que a mandioca esteja pronta para a produção da farinha; à razão entre a quantidade de mandioca in natura e a farinha produzida; o tempo necessário para a produção da farinha; ao preço de venda da farinha, entre outras. Os dados e informações coletados foram organizados na forma de texto.

Com o texto escrito, retornamos à comunidade; desta feita, conversamos com o Sr Diomar Antônio de Farias, apresentando-lhe o que havíamos elaborado. O texto foi lido e discutido. Recebeu contribuições, no sentido de adequar termos/ conceitos que são utilizados pelas pessoas no processo de produção da farinha de mandioca.

Os encaminhamentos metodológicos desencadeados no processo de coleta de dados e informações foram estabelecidos a partir dos estudos que tratam sobre a pesquisa qualitativa voltadas à etnografia (MALINOWSKI, 1976; EZPELETA; ROCKWELL, 1989; CHIZOTTI, 1991; ANDRÉ, 2005;). Isso nos possibilitou olhar, de modo mais acurado, para o processo de investigação, além de contribuir, decisivamente, no processo de análise dos dados e informações coletadas.

Participaram como sujeitos da pesquisa Ruimar Antônio de Farias, Rosalina Francisco Machado, Diomar Antônio de Farias, Altina de Farias Machado, Jefferson Ribeiro de Queiroz, Rosemiro Antônio de Farias e Helena Ferreira da Silva. 


\section{Um olhar na perspectiva do Programa Etnomatemática}

O entendimento que temos sobre o Programa Etnomatemática proposto por D'Ambrosio é de que ele nos possibilita fazer uma (re)leitura da matemática que se faz presente nos diferentes contextos culturais, incluindo-se aqui, a academia. Trata-se, portanto de compreender a matemática como componente cultural, o que é diferente da concebê-la na perspectiva hegemônica ocidental.

Entender a matemática como elemento cultural, significa, antes de tudo, respeitar o modo característico de como as pessoas de um dado grupo social fazem uso de quantidades, medidas, formas e operações. Para tanto, cada cultura elabora sua lógica de lidar com as quantidades, as formas de estabelecer comparações, classificar, medir e operar com números, isso significa matematizar.

Os processos de contagem, de medições, e de operar com números ou, ainda, com quantidades, ocorrem de maneiras diferentes nas diferentes culturas "e transformam-se ao longo do tempo. Eles sempre revelam as influências do meio e organizam-se com uma lógica interna, codificam-se e formalizam-se. Assim nasce a matemática." (D’AMBROSIO, 1993, p. 35).

A identificação de saberes e fazeres como prática cultural da Comunidade Quilombola Lagoa da Pedra, a qual está inserida num contexto social mais amplo, assim como a cultura dos grupos marginalizados, está sujeita às transformações de toda a natureza. Mesmo com a ingerência de uma cultura hegemônica, é bastante comum encontrar elementos culturais peculiares que se manifestam nos modos de fazer, de ser, de se organizar no grupo, de falar, na religiosidade, nos festejos, nas tradições. As transformações são provocadas pelo processo de trocas e experiências entre as diferentes culturas.

Normalmente, as ideias matemáticas presentes em contextos culturais nos quais as pessoas apresentam baixo nível de escolarização localizam-se no domínio da matemática elementar, o que não significa que tais ideias/conceitos sejam vistos ou encarados pelas pessoas que os utilizam, como matemática. Nesse sentido, a Etnomatemática "visa explicar os processo de geração, organização e transmissão de conhecimento em diversos sistemas culturais e as forças interativas que agem nos e entre os processos" (D’ AMBROSIO, 1993, p. 7).

Os povos conquistados/dominados foram, na maioria dos casos, ignorados e, às vezes, proibidos de divulgar suas especificidades intelectuais. Dessa maneira, desapareceram modos tradicionais de medir, organizar e quantificar conjuntos de objetos, assim como o desaparecimento de religiões, línguas, 
conhecimentos sobre ervas medicinais e tantas outras formas de expressões culturais. Esse também foi um processo de sobreposição da cultura dominante (D'AMBROSIO, 2002).

D'Ambrosio entende a matemática como uma estratégia desenvolvida pela espécie humana, ao longo de sua historia, para explicar, para entender, para manejar e conviver com a realidade sensível, perceptível, e com o imaginário. Obviamente, dentro de um contexto natural e cultural em que os grupos sociais estão inseridos.

O Programa Etnomatemática tem origem na busca de entender o fazer e o saber matemático de culturas periféricas e marginalizadas. Ele não se esgota no entender o conhecimento (saber e fazer) da cultura de um grupo social. Para tanto, é necessário conhecer também a cultura dominante, principalmente porque essa tende a minimizar as produções das culturas diferentes.

Desde sua concepção, o termo Etnomatemática vem passando por uma série de interpretações e entendimentos. Desde a década de 1970, D’Ambrosio vem escrevendo sobre Etnomatemática.

Etno é hoje aceito como algo muito amplo, referente ao contexto cultural, e, portanto inclui considerações como linguagem, jargão, códigos de comprimentos, mitos e símbolos; matema é uma raiz difícil, que vai na direção de explicar, de conhecer, de entender; tica vem sem dúvida de techne, que é a mesma raiz de arte e de técnica. Assim, poderíamos dizer que Etnomatemática é a arte ou técnica de explicar, de conhecer, de entender nos diversos contextos culturais. (D'AMBROSIO, 1990, p. 5).

A Etnomatemática toma como referência a produção dos sujeitos em seus contextos culturais, o que exige, em grande parte, a compreensão da cultura e das relações entre a matemática presente nos currículos escolares e a matemática da vida cotidiana. Assim, é importante reconhecer na Etnomatemática um programa de pesquisa que caminha juntamente com uma prática escolar.

A Etnomatemática é uma das tendências mais importantes da Educação Matemática e deve fazer parte de toda a formação do educador matemático. Ela é parte integrante da vida e do contexto em que as pessoas vivem, assim, a apreensão da realidade cultural e nela, a matemática, se faz de fato quando o aprendiz vivencia as situações e consegue identificar, no saber étnico, o conteúdo a ser modelado em matemática na sala de aula. (FERREIRA, 1997).

As diferentes maneiras de fazer (prática) e de saber (teorias), que 
caracterizam uma cultura, são partes do conhecimento compartilhado e do comportamento compatibilizado. Assim como comportamento e conhecimento, as maneiras de saber e de fazer estão em permanente interação e possibilitam a existência das comunidades ou povos distintos. (D'AMBROSIO, 2002).

A proposta da Etnomatemática não significa a rejeição da matemática acadêmica, e sim, aprimorar e incorporar a ela valores de humanidade. "É um grande equívoco pensar que a Etnomatemática pode substituir uma boa matemática acadêmica.” (D’AMBROSIO, 2002, p. 43).

Alguns matemáticos oferecem resistência em aceitar a Etnomatemática como ramo de pesquisa que traz em seu bojo reflexões sobre a implantação de uma proposta educacional que leve em conta a história, a cultura e as questões antropológicas da matemática originária e praticada no do dia-a-dia da dinâmica familiar. (GIRARDI, 200[5]).

Segundo D'Ambrosio (200[5]), ao admitir que existe mais de uma matemática, aceitamos que existem diversas respostas a ambientes diferentes. Assim, pode haver mais de uma maneira de explicar e de compreender a realidade. Na perspectiva de Vilela (2007), trata-se de jogos de linguagem.

Nosso entendimento é de que a matemática acadêmica deve lançar seu olhar sobre os modos de fazer e de saber da população e, a partir das reflexões sobre esse olhar, traçar linhas de ação para o saber, de modo que as pessoas acessem tanto o que é produzido pela academia quanto o que é praticado nos diferentes contextos sociais. Para Vergani (2007), o sistema universitário deve impedir que o ensino superior mantenha a cegueira matemática em relação às demandas do Ensino Fundamental e Médio, o que alimenta a exclusão social.

\section{A Produção da farinha de mandioca}

A produção da farinha de mandioca na Comunidade Lagoa da Pedra ainda ocorre de forma artesanal ${ }^{2}$. São necessários, pelo menos, dois dias de trabalho para se produzir cerca de $150 \mathrm{Kg}$ de farinha. O processo de produção envolve, ainda, as tarefas de coleta da madeira, limpeza da casa de farinha, colheita e preparação da mandioca.

A produção da farinha de mandioca compreende doze etapas: a

\footnotetext{
${ }^{2}$ Jesus (2007), relata que o processo de produção da farinha de mandioca na Comunidade Kalunga do Riachão ocorre de forma artesanal. Registra-se que há uma série de elementos e artefatos semelhantes no processo de produção da farinha de mandioca entre as Comunidades Kalunga do Riachão e Lagoa da Pedra.
} 
preparação do solo, o plantio, a colheita, a raspagem, a lavagem, a ralação, a lavagem da massa, a prensagem, a peneiração da massa (sessar a massa), a torração, a peneiração da farinha (sessar a farinha) e o acondicionamento da farinha.

Escolhe-se o terreno e prepara-se o solo, fazendo uso de trator e/ou enxada. A preparação do solo geralmente é feita no início do período chuvoso (setembro a novembro) e o plantio se estende de setembro até janeiro.

Para o plantio são utilizadas partes do caule da mandioca arrancada. $\mathrm{O}$ caule é cortado com facão, produzindo-se a maniva. Cada maniva mede entre 10 e $15 \mathrm{~cm}$ e deve conter cerca de 5 (cinco) pitonguinhos (gemas), de onde nascem as raízes e os brotos, que, ao se desenvolverem, constituirão um novo pé de mandioca.

Com o terreno preparado inicia-se o processo de plantio. Usando a enxada, são abertas pequenas covas onde são colocadas as manivas (uma por cova), e com o pé, joga-se terra de forma a cobrir as manivas.

As covas são abertas em fileiras, com espaçamento de aproximadamente 01 (um) metro entre si. A distância entre as fileiras também é de aproximadamente 01 (um) metro. Para efetuar a medida entre as fileiras e as covas são utilizadas partes do corpo, principalmente as pernas (a cada passo faz-se uma cova).

A colheita da mandioca é feita pelas pessoas da própria família ou com a ajuda dos vizinhos (um sistema de troca de serviços), e acontece com o sol das primeiras horas da manhã e ao entardecer.

Ao arrancar o pé de mandioca separam-se, com as mãos, as raízes do caule. As raízes arrancadas são amontoadas, assim como são amontoadas as ramas (caules). Dos montes, as raízes são levadas para o carro de boi ou carreta do trator, em balaios (cestos feitos de taboca) ou em carrinho de mão e, em seguida, transportadas para a casa de farinha. As ramas, das quais se extrai as manivas, são transportadas para um local onde fiquem protegidas do sol.

A quantidade de mandioca a ser arrancada depende da quantidade de farinha a ser produzida, geralmente arranca-se entre 10 a 16 carrinhos. O cálculo é feito por meio de estimativa, tendo como referência a razão entre o peso da quantidade de mandioca in natura e o peso da quantidade de farinha a ser produzida. A referência utilizada é de que a cada tonelada de raízes de mandioca obtém-se $170 \mathrm{Kg}$ de farinha.

Costumeiramente, estima-se o peso das raízes de mandioca pelo espaço 
ocupado no carro de boi. Segundo Seu Diomar, o carro de boi comporta uma tonelada de raízes, o que equivale a 14 carrinhos de mão ou 28 balaios. Temos, aqui, uma relação de equivalência: 1 carro de boi equivale a 14 carrinhos, que equivale a 28 balaios e se produz $170 \mathrm{Kg}$ de farinha. Na farinheira, as raízes são colocadas em local com sombra, onde se faz a raspagem da casca e em lugar que não atrapalhe a sequência dos trabalhos. Ao redor do monte de raízes são dispostas cadeiras de madeira ou tamboretes, a fim de que pessoas se acomodem para efetuar a raspagem, que consiste na remoção da casca, o que é feito manualmente com o auxílio de faca bem amolada.

Normalmente, pessoas de outras famílias auxiliam no processo de raspagem. Enquanto se efetua a raspagem, as pessoas contam causos, relembram velhos tempos, contam histórias, o que cria um ambiente agradável e um momento de descontração. Esses momentos fortalecem os laços de amizade entre as pessoas. Nos termos de Jesus (2007, p. 142), este é um "momento de geração, organização e difusão de conhecimentos matemáticos, adquiridos, a princípio, pela empiria e, em seguida, sistematizados dentro do contexto social em questão e transmitidos por meio da comunicação oral, gestual ou comportamental."

As raízes raspadas são colocadas em bacias feitas de pneus de caminhão, posteriormente são lavadas em uma gamela contendo água e depois colocadas em uma cama. A cama é um espaço contornado por quatro pedaços de madeira, sobre os quais estende-se um pedaço de lona de plástico, de modo a cobrir o chão. A cama fica próxima ao ralador.

Da cama as raízes são levadas ao ralador movido por um motor elétrico. No ralador elas são pressionadas manualmente sobre o cilindro com dentes metálicos na forma serrilhada, por meio de um furo circular acoplado em uma caixa de madeira.

A mandioca ralada forma uma massa densa e espessa, que cai diretamente numa gamela, colocada em posição horizontal, sob o ralador. Para evitar o transbordamento, parte da massa é distribuída na gamela por meio de um rodo, instrumento, este, que depois é utilizado para mexer a farinha quando do processo de torração.

$\mathrm{O}$ rodo é feito de madeira e se assemelha a uma enxada. O cabo comprido possibilita que a pessoa que está cuidando da torração da farinha mantenha-se o mais afastado possível do calor do fogo e revirar (mexer) a massa.

Da gamela a massa é transladada para outra gamela, colocada próxima àquela que fica sob o ralador. Parte dessa massa é depositada na bacia de 
pneu de caminhão que contém água. Na bacia, a massa é diluída na água. Esse processo é denominado de lavagem da massa.

Mergulha-se na bacia um saco de linhagem (ráfia) com uma das extremidades aberta e em seguida o mesmo é erguido. Dentro dele fica parte da massa diluída em água. Escorre-se a água e retira-se do saco a massa lavada, a qual é depositada em outra bacia de pneu. Esse procedimento é repetido várias vezes, até que se retirem os grânulos da massa (parte sólida). Trata-se de um processo de coar.

Dilui-se outra quantidade de massa, nessa mesma água, e repete-se todo o procedimento novamente. Esse processo é repetido várias vezes. Assim, a água fica com uma grande concentração de fúrcula (fécula - amido ou polvilho).

A água com grande concentração de polvilho fica em repouso de um dia para o outro, para que este decante. Retira-se toda água que ficou sobre o polvilho, coloca-se um pano sobre ele e sobre o pano coloca-se cinza. A cinza absorve grande parte da umidade do polvilho, o que facilita na secagem. Temse, com isso, a tapioca, a qual é utilizada na produção de bolos ou beiju.

Segundo dona Rosa, lava-se um terço de toda massa. A lavagem de parte da massa é feita para que a farinha não fique encardida (amarelada) e para não ficar muito leve. A massa lavada é misturada de forma homogênea com o restante da massa (a não lavada).

A massa é colocada em sacos de linhagem e ajeitada, de modo que se pareça com uma almofada, os quais são levados à prensa e acomodados uns sobre os outros.

Na prensa são colocadas entre quatro e cinco camadas de almofadas de massa, cada uma delas com três almofadas. Para que ocorra a eliminação de grande parte do líquido (veneno), a massa é mantida na prensa por um período entre 12 e 14 horas. Findo o processo de prensagem obtém-se uma massa consistente, a qual passa a ser sessada (peneirada).

Sobre o caixote da prensa encontra-se uma tampa (tábua), que acomodada sobre as almofadas, pressiona-as para eliminar o líquido.

A peneiração consiste na retirada da crueira (pequenos pedaços de mandioca remanescentes da ralação). A crueira é colocada ao sol para secar. Depois, ela é pilada (triturada) no pilão e pode ser utilizada na produção de bolos e do beiju.

A massa peneirada é colocada, aos poucos, no tacho, devendo ser espalhada e mexida com uma espécie de facão de buriti (uma espécie de palmeira, planta nativa na região). Quando no tacho houver uma quantidade 
entre 20 e 25 quilos de massa, ela passa a ser mexida com o rodo.

O tacho é um recipiente metálico, com formato retangular, acoplado sobre um suporte construído com adobe (tijolo de barro cru). Sob o tacho encontra-se o forno, no qual há uma abertura por onde se introduz a madeira, ateando-se fogo para aquecer o tacho.

A temperatura do tacho tem que ser elevada o suficiente para que se efetue o processo de torração. A massa deve ser constantemente mexida para que o processo de torração ocorra de forma homogênea e que não fiquem grânulos queimados.

Leva-se em torno de 2 a 3 horas para secar uma quantidade entre 15 e 40 litros de farinha de mandioca. No final desse tempo, retira-se o fogo, continuando a mexer a farinha até que a temperatura baixe. Inicia-se, assim, a segunda peneiração (sessagem), na qual se retiram os grânulos maiores (caroços), os quais são descartados.

Ao finalizar o processo de torração, a farinha de mandioca é recolhida em um canto do tacho para ser acondicionada em sacos de linhagem. Segundo Seu Diomar, um saco comporta 80 litros de farinha. O litro é um recipiente, normalmente metálico e cilíndrico, proveniente da embalagem de algum produto, óleo de soja, por exemplo. Um litro de farinha pesa, aproximadamente, $650 \mathrm{~g}$.

\section{Identificando ideias matemáticas}

Adentrando na cultura da produção da farinha de mandioca, observamse uma série de ideias/conceitos matemáticos. Iniciando na preparação do solo para o plantio da mandioca, perpassando pelo processo de produção da farinha e mesmo retirada dos subprodutos. Marca, assim, um sutil e amplo processo de transmissão de saberes de uma tradição que perpassa por gerações.

Neste caso, a matemática deve ser interpretada como uma prática construída socialmente (VILELA, 2007), que vincula seu surgimento e desenvolvimento nas atividades necessárias à sobrevivência (JESUS, 2007). Trata-se de considerar as ideias matemáticas como pressupostos mais amplos do que o simples fato de contar, ordenar, medir e classificar que se fazem presente na realidade em que os sujeitos estão inseridos (D’AMBROSIO, 2002).

Mesmo sabendo da existência de um sistema convencional de medidas, na preparação do solo os moradores da Lagoa da Pedra fazem uso de um sistema de medidas agrárias não convencionais (braça, quadra, tarefa) e no plantio utilizam partes do corpo para efetuar medidas (pernas - passos). 
Em relação às medidas é possível estabelecer uma relação de equivalência ( 1 braça $=2,2 \mathrm{~m}$; 1 quadra tem 15 braças de lado; 1 tarefa $=4$ quadras). A quadra e tarefa apresentam equivalência entre si (1 quadra $=15$ braças de lado $=33 \mathrm{~m}$ x $33 \mathrm{~m}=1089 \mathrm{~m}^{2} ; 1$ tarefa $=4$ quadras ou $4.356 \mathrm{~m}^{2}=4$ x $1089 \mathrm{~m}^{2}$ ).

Para verificar a distância entre as mudas e as fileiras utiliza-se o passo, o qual equivale a $1 \mathrm{~m}$.

No auxílio que uma família presta à outra, quando da produção da farinha de mandioca ou mesmo do cultivo da lavoura (troca de tarefas), também se observa equivalência, quer seja na reposição do tempo trabalhado, quer seja no valor a ser pago, dependendo do acordo previamente estabelecido.

De acordo com D'Ambrosio (1990), podemos falar em etno, matema e ticas. Etno pode ser vista no modo como os Quilombolas da Lagoa da Pedra dimensionam o espaço para o plantio das manivas. Matema pode ser identificada no conhecimento de que se faz necessária uma distância de, pelo menos um passo, entre uma muda de mandioca e outra. A tica explica que a distância de um passo entre uma muda e outra é suficiente para que as raízes se desenvolvam.

Existem elementos importantes a observar quando do plantio, quais sejam: o período para o plantio; o tipo de solo; a qualidade das manivas; a ocorrência de chuvas; a remoção das ervas daninhas; o controle de pragas; o tempo necessário para que a mandioca se desenvolva e fique pronta para a colheita; entre outros. Ter conhecimentos desses elementos e articulá-los entre si, de modo a que a produção seja adequada e suficiente para a produção da farinha de mandioca necessária ao sustento da família, temos etno, matema e ticas. (D’AMBROSIO, 1990).

Em todo o processo de produção da farinha de mandioca observamos relações entre quantidades, as quais permitem, por exemplo, fazer estimativas e mesmo encontrar valores exatos.

As relações de medidas aparecem nas diferentes etapas do processo de produção da farinha de mandioca. Isso significa que os produtores da farinha de mandioca na Lagoa da Pedra articulam e dimensionam as relações de medidas de acordo com suas próprias estimativas e por meio de sistemas comparativos; fazem uso de recipientes disponíveis na comunidade para estabelecer relações e aferir quantidades. Essa forma de estabelecer relação, bem como os instrumentos de fabricação, aparentemente não tem razão aos olhos da matemática acadêmica, mas são funcionais para os produtores de farinha da comunidade em estudo. 
O modo como essas pessoas fazem uso das medidas caracteriza a forma de matematizar desse grupo cultural (D’AMBROSIO, 1998). Trata-se, portanto, de auscultar esses saberes e tratá-los de forma respeitosa, reconhecendo assim sua eficácia e funcionalidade para o contexto social em que o grupo está inserido. Temos aqui novamente etno, matema e tica de que nos fala D'Ambrosio (1990).

Apelamos para que a academia não fique de olhos vendados a esses saberes e fazeres, e que os trate como parte integrante da cultura de um povo que luta, incansavelmente, pela melhoria da qualidade de vida.

Ao procurar estabelecer relações mais precisas entre as estimativas aqui apresentadas e o que o sistema convencional recomenda, incorremos no risco de sublimar os conhecimentos dessa população. Estamos dizendo que isso merece um cuidado especial e requer dos pesquisadores um trabalho cuidadoso e sistemático, de modo a não impor o olhar acadêmico em algo que é característico de uma prática sociocultural.

O interessante é que as medidas utilizadas conseguem atingir os objetivos, no propósito de resolução de problemas dessa comunidade, problemas esses, imersos numa dada realidade social e cultural.

No processo da torração observamos a representação do tempo, registrado pelas horas e minutos, o que não significa exatidão, como muitas vezes ocorre num processo de produção industrial, por exemplo. O tempo de torração da farinha (02 e/ou 03 horas) se consolida quando, a olho nu e/ou pelo gosto da farinha, os produtores a consideram de qualidade. Novamente, trata-se de conhecimentos práticos em que se combinam tempo (duração em horas), aspecto (cor, textura) e sabor.

Lançando um olhar sobre as representações das figuras geométricas apresentadas em livros didáticos de matemática, percebemos que muitas delas se fazem presente nos utensílios e instrumentos produzidos na comunidade. Como exemplo, podemos destacar a peneira, o quibano, o facão feito de madeira, a prensa, o balaio, o cocho, o rodo, a gamela, o carro de boi, o carrinho de mão, entre outros. Neles encontramos formas geométricas unidimensionais, bidimensionais e tridimensionais, o que nos permite falar em geometria plana e espacial.

A Etnomatemática nos permite entender as práticas, considerando que cada sujeito interpreta suas vivências e experiências a partir de relações oriundas da herança cultural herdada dos seus ancestrais. Muitas dessas práticas exigem contatos quase constantes com medidas lineares, superficiais e volumétricas, na maioria das vezes em diferentes situações e contextos, dependendo da atividade que está sendo desenvolvida. 
A dinâmica do movimento de busca de solução às situações exige o estabelecimento de geração de estratégias e procedimentos, inclusive para a confecção de artefatos (D’AMBROSIO, 1998). Muitas vezes, os artefatos exigem medidas exclusivas e diferenciadas, que, ao estabelecerem relação com o que já se dispõe, permitem a geração de novos produtos.

Nessa perspectiva, cada sujeito conserva e produz novos saberes matemáticos nas construções de utensílios, tendo como matéria-prima os elementos presentes no ambiente em que vive. Esses dados e informações nos permitem inferir que se faz mister um estudo mais acurado em relação a etno, matema e tica de que nos fala D’Ambrosio (1990).

\section{$7 \mathrm{O}$ acondicionamento da farinha: algumas considerações}

Destacamos que os elementos da cultura da Comunidade Quilombola Lagoa da Pedra são importantes do ponto de vista de novas pesquisas. Transitamos por eles porque a cultura da comunidade está entranhada no ser e faz parte da vida das pessoas.

Observando e trabalhando no processo de produção da farinha de mandioca, indo em busca dos conhecimentos construídos, organizados e mantidos pelos sujeitos da comunidade, identificamos uma série de ideias/conceitos matemáticos, desenvolvidos, certamente, no desenrolar da vida cotidiana. Esses elementos corroboram com as pesquisas realizadas por Vilela (2007) e Jesus (2007). Possivelmente, muitos dos conhecimentos matemáticos em uso foram produzidos pelos antepassados e sem saber da existência de uma Ciência Matemática.

Ao desenvolver esse trabalho de pesquisa, encontramos elementos que, antes, passavam despercebidos aos nossos olhos. Nesse sentido, destacamos as doze etapas porque passa o processo de produção da farinha de mandioca; as permanências e mudanças que ocorreram quer sejam no processo ou mesmo nos artefatos. Muitos dos elementos indicados aqui também podem ser vistos nos estudos de Jesus (2007).

Em relação às ideias matemáticas presentes no processo de fabricação da farinha de mandioca destacamos as relações entre medidas convencionais e não convencionais e nelas entre si, sobretudo nas relações entre a área cultivada e a quantidade de produção; entre a área e a quantidade de pés de mandioca plantados; entre a capacidade que o carro de boi comporta e a quantidade de mandioca produzida, com balaio e o carrinho de mão; entre o peso das raízes e 
a quantidade de farinha de mandioca produzida; entre a quantidade de mandioca in natura e a quantidade de fornadas de farinha; entre a quantidade de massa e o tempo necessário para a torração; entre a quantidade que uma saca de farinha comporta e seu peso; entre o litro de farinha e o peso.

Destacamos, ainda, os termos utilizados para identificar os artefatos e/ ou quantidades (carro de boi, carretão, sessar, facão de madeira, rodo, tapiti, quibano, peneira, gamela ou masseira, prensa, bacia de pneu, braça, quadra, tarefa, troca de serviço, forno, tacho, cocho, crueira, litro, balaio, carrinho de mão, cesto, pilão, fogão, entre outros), termos que merecem ser estudados e que possibilitam escrever um dicionário dos termos dos Quilombolas da Lagoa da Pedra.

Em relação às ideias/conceitos matemáticos temos que mencionar elementos da geometria plana e espacial que se fazem presentes nos artefatos, por exemplo, formas unidimensionais, bidimensionais e tridimensionais.

Sobressaem, ainda, as medidas de tempo, que são usuais desde o processo de preparação do solo para o cultivo da mandioca, perpassando pela maturação e o tempo necessário para produzir uma dada quantidade de farinha. Destarte, muito do que dissemos em relação ao processo de produção da farinha de mandioca e aos sistemas de medidas pode ser visto também na pesquisa de Jesus (2007).

Esses dados e informações nos permitem inferir que se faz mister um estudo mais acurado em relação a etno, matema e tica de que nos fala D’Ambrosio (1990). Assim “(...) olhar as práticas matemáticas como jogos de linguagem", tem-se a possibilidade do distanciamento da matemática acadêmica como referência exclusiva (VILELA, 2007, p. 237). Acreditamos, igualmente, que os dados presentes nessa pesquisa possibilitam o desenvolvimento de trabalhos com vistas ao translado de conhecimentos presentes no processo de produção da farinha de mandioca para fins didáticos.

\section{Referências}

ANDRÉ, M. Etnografia da pratica escolar. São Paulo: Papirus, 2005.

BRASIL. Constituição da República Federativa do Brasil. Brasília: Senado Federal, Centro Gráfico, 1997.

BRITTO, M. R. F. Aprendizagem significativa e a formação de conceitos na escola. In. BRITO, M. R. F. (Org) Psicologia da Educação Matemática: Teoria e pesquisa. Florianópolis: Insular. 2001, p. 69-84. 
CHIZZOTTI, A. Pesquisa em ciências humanas e sociais. São Paulo: Cortez, 1991.

COSTA, W. N. G.; SILVA, V. L. Matemática mítico-religiosa-corporal do negro brasileiro. In: Scientific american: Etnomatemática. Pinheiros, Brasil, v. único, n. 35, edição especial, 200[5].

DAMASCENO, A. V. C. A cultura da produção de farinha: um estudo da matemática nos saberes dessa tradição. Natal: UFRN, 2005.

D'AMBROSIO, U. Etnomatemática: elo entre as tradições e a modernidade. 2. ed. Belo Horizonte: Autentica, 2002. (Coleção Tendências em Educação Matemática).

D’AMBROSIO, U. Etnomatemática. 4. Ed. São Paulo: Editora Ática, 1998.

D’AMBROSIO, U. Etnomatemática. São Paulo: Ática, 1993.

D'AMBROSIO, U. Etnomatemática: Arte ou Técnica de explicar e conhecer. São Paulo: Ática, 1990.

D’AMBROSIO, U. Volta ao mundo em matemática. In: Scientific American, Etnomatemática. Pinheiros, Brasil: Brasil, v. único, n. 35, edição especial, 200[5].

EZPELETA, J.; ROCKWELL, E. Pesquisa participante. São Paulo: Cortez, 1989.

FERREIRA, E.S. Etnomatemática uma proposta metodológica. Mestrado em Educação Matemática (MEM), Universidade Santa Úrsula (USU), Rio de Janeiro, 1997.

GIRARDI, G. Por que Etnomatemática? In: Scientific American, Etnomatemática. Pinheiros, Brasil, v. único, n. 35, edição especial. 2005.

JESUS, E. A. A Comunidade Kalunga do Riachão: um olhar etnomatemático. Goiânia: Editora da UCG, 2007. (Coleção: Goiânia em prosa e verso).

LÉVI-STRAUSS, C. Antropologia estrutural I. Rio de Janeiro: Tempo Brasileiro, 1975.

MALINOWSKI, B. Os Argonautas do Pacífico Ocidental. São Paulo: Abril Cultural, 1976. (Malinowski, Coleção Os Pensadores).

SILVA, T. T. Documentos de Identidade: uma introdução às teorias do Currículo. 2. ed. Belo Horizonte: Autêntica, 2002.

VERGANI, T. Educação Etnomatemática: O que é? Natal: Editora Flecha do Tempo, 2007. 
VILELA, D. S. Matemáticas nos usos e jogos de linguagem: ampliando concepções na educação matemática. 2007, s/n. Tese (Doutorado em Educação) - Faculdade de Educação, Universidade Estadual de Campinas (UNICAMP), Campinas, 2007. Disponível em: <http://www.educadores.diaadia.pr.gov.br/arquivos/File/2010/ artigos_teses/2011/matematica/maio/tese_denise_silva_vilela.pdf $>$. Acesso em: 02 jun. 2011.

Submetido em Abril de 2011. Aprovado em Julho de 2011. 